\title{
P152 Prediction of Death or Heart Failure-related Hospitalizations by Cardio-ankle Vascular Index (CAVI) and $\mathrm{CAVI}_{0}$
}

\author{
Bart Spronck ${ }^{1,2}$, Jonathan Lee ${ }^{3,4}$, Garrett Oldland ${ }^{3,4}$, Mary Jo Obeid ${ }^{3}$, Mahati Paravathaneni ${ }^{3}$, Naga Vaishnavi Gadela ${ }^{3}$, \\ Armghan Ans $^{3}$, Gurpreet Singh ${ }^{3,5}$, Rushik Bhuva ${ }^{3}$, Scott Akers ${ }^{4}$, Julio Chirinos ${ }^{6}$ \\ ${ }^{1}$ Department of Biomedical Engineering, School of Engineering and Applied Science, Yale University, New Haven, CT, USA \\ ${ }^{2}$ Department of Biomedical Engineering, CARIM School for Cardiovascular Diseases, Maastricht University, Maastricht, The Netherlands \\ ${ }^{3}$ Hospital of the University of Pennsylvania, Philadelphia, PA, USA \\ ${ }^{4}$ Philadelphia VA Medical Center, Philadelphia, PA, USA \\ ${ }^{5}$ Rowan University School of Osteopathic Medicine, Stratford, NJ, USA \\ ${ }^{6}$ University of Pennsylvania Perelman School of Medicine, Philadelphia, PA, USA
}

\section{ABSTRACT}

Background: Arterial stiffness as measured by carotid-femoral pulse wave velocity (PWV) has been shown to predict cardiovascular events [1]. However, PWV is blood pressure (BP) dependent [2,3] leading to the development of cardio-ankle vascular index (CAVI) as a more blood pressure-independent index [4] that also shows predictive ability in Asian populations [5]. Recently, CAVI was further refined into $\mathrm{CAVI}_{0}$ [6], removing residual acute blood pressure dependence [7]. The present study aims to assess risk prediction by CAVI and CAVI in a US population.

Methods: We enrolled 156 subjects (94.8\% male; 47.7\% African-American) with and without heart failure. Subjects underwent arterial stiffness assessments (VaSera 1500 N, Fukuda Denshi Co., Tokyo, Japan). Left (L-CAVI) and right (R-CAVI) measurements were obtained from the device, CAVI 's were converted from CAVI's taking into account CAVI's scale coefficients $[8,9]$. We prospectively followed participants for a mean of 2.56 years for the composite endpoint of death or heart failure related hospital admission.

Results: L-CAVI and R-CAVI did not differ significantly (9.80 \pm 2.11 vs $9.66 \pm 1.92, p=0.146$ ); neither did L-CAVI ${ }_{0}$ and $\mathrm{R}_{-} \mathrm{CAVI}_{0}(16.51 \pm 5.85$ vs $16.15 \pm 5.34, p=0.178)$. In unadjusted Cox regression, R-CAVI, L-CAVI, and R-CAVI ${ }_{0}$ but not L-CAVI predicted outcome (Table 1). After adjustment for age, sex, race, and systolic BP, only right-sided CAVIs and CAVI $\mathrm{s}_{0}$ were predictive.

Discussion: We observed possible body-side differences in prediction using CAVI and $\mathrm{CAVI}_{0}$. A previous study crosssectionally reported more pronounced body side differences in heart-to-ankle PWV related to cardiovascular disease [10]; we

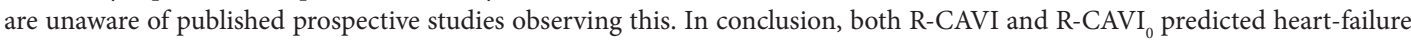
related end-points.

Table Cox regression results

\begin{tabular}{lccl}
\hline & $\boldsymbol{n}$ & Standardized HR [95\% CI $]$ & $\boldsymbol{p}$ \\
\hline Unadjusted & \multicolumn{3}{c}{} \\
L-CAVI & 155 & $1.33[1.01-1.76]$ & $\mathbf{0 . 0 4 2}$ \\
R-CAVI & 156 & $1.52[1.10-2.11]$ & $\mathbf{0 . 0 1 1}$ \\
L-CAVI $_{0}$ & 155 & $1.28[0.97-1.68]$ & 0.078 \\
R-CAVI $_{0}$ & 156 & $1.39[1.04-1.87]$ & $\mathbf{0 . 0 2 7}$ \\
Adjusted for age, sex, race, and systolic BP & \\
L-CAVI & 154 & $1.35[0.99-1.83]$ & 0.06 \\
R-CAVI & 155 & $1.55[1.08-2.21]$ & $\mathbf{0 . 0 1 6}$ \\
L-CAVI $_{0}$ & 154 & $1.30[0.95-1.77]$ & 0.10 \\
R-CAVI $_{0}$ & 155 & $1.39\left[1.0^{\prime}-1.9^{\prime}\right]$ & $\mathbf{0 . 0 4 4}$ \\
\hline
\end{tabular}

s-HR, standardized hazard ratio; $\mathrm{CI}$, confidence interval. 


\section{REFERENCES}

[1] Vlachopoulos C, Aznaouridis K, Stefanadis C. Prediction of cardiovascular events and all-cause mortality with arterial stiffness: a systematic review and meta-analysis. J Am Coll Cardiol 2010;55:1318-27.

[2] Bramwell JC, McDowall RJS, McSwiney BA. The variation of arterial elasticity with blood pressure in man (Part I). Proc R Soc Lond B 1923;94:450-4.

[3] Spronck B, Heusinkveld MH, Vanmolkot FH, Roodt JO, Hermeling E, Delhaas T, et al. Pressure-dependence of arterial stiffness: potential clinical implications. J Hypertens 2015;33:330-8.

[4] Shirai K, Utino J, Otsuka K, Takata M. A novel blood pressure-independent arterial wall stiffness parameter; cardio-ankle vascular index (CAVI). J Atheroscler Thromb 2006;13:101-7.

[5] Matsushita K, Ding N, Kim ED, Budoff M, Chirinos JA, Fernhall B, et al. Cardio-ankle vascular index and cardiovascular disease: Systematic review and meta-analysis of prospective and cross-sectional studies. J Clin Hypertens (Greenwich) 2019;21:16-24.

[6] Spronck B, Avolio AP, Tan I, Butlin M, Reesink KD, Delhaas T. Arterial stiffness index beta and cardio-ankle vascular index inherently depend on blood pressure but can be readily corrected. J Hypertens 2017;35:98-104.

[7] Mestanik M, Spronck B, Jurko A, Mestanikova A, Jurko T, Grendar M, et al. Enchanced cardio-ankle vascular index (CAVI0) is experimentally less blood pressure dependent than standard CAVI. J Hypertens 2019;37:e209.

[8] Takahashi K, Yamamoto T, Tsuda S, Okabe F, Shimose T, Tsuji Y, et al. Coefficients in the CAVI equation and the comparison between CAVI with and without the coefficients using clinical data. J Atheroscler Thromb 2019;26:465-75.

[9] Spronck B, Mestanik M, Tonhajzerova I, Jurko A, Tan I, Butlin M, et al. Easy conversion of cardio-ankle vascular index into CAVI0: influence of scale coefficients. J Hypertens 2019;37:1913-14.

[10] Yeragani VK, Kumar R, Bar KJ, Chokka P, Tancer M. Exaggerated differences in pulse wave velocity between left and right sides among patients with anxiety disorders and cardiovascular disease. Psychosom Med 2007;69:717-22.

(c) 2019 Association for Research into Arterial Structure and Physiology. Publishing services by Atlantis Press International B.V. This is an open access article distributed under the CC BY-NC 4.0 license (http://creativecommons.org/licenses/by-nc/4.0/). 